\title{
Capsule Commentary on Ackerman et al., When to Repatriate? Clinicians' Perspectives on the Transfer of Patient Management from Specialty to Primary Care
}

\author{
Jeffrey L Jackson, MD MPH and Ketan Nadkarni, BS
}

Medical College of Wisconsin, Milwaukee, WI, USA.

J Gen Intern Med 29(10): 1389

DOI: $10.1007 / \mathrm{s} 11606-014-2958-\mathrm{y}$

(c) Society of General Internal Medicine 2014

$\mathrm{T}$ he question of when patients can stop seeing specialists and instead be managed exclusively by their primary care providers (PCPs) is an important one. Studies have examined the transition of care among patients surviving cancer, ${ }^{1,2}$ though the literature on other health conditions is limited. ${ }^{3}$ In a mixed methods study, Ackermann and colleagues found that there was agreement between the PCP and the specialist comanaging patients for about half of patients, with $16 \%$ of patients deemed appropriate for transfer to primary care and $36 \%$ appropriate for continued co-management. ${ }^{4}$ Among the remaining $48 \%$ of patients in which there was disagreement, specialists were half as likely to deem patients appropriate for transfer back to primary care.

In interviews with PCPs, reasons for this discordance included lack of specialist belief in the PCP's abilities, financial incentives for specialists to continue to follow stable patients, and patient preference to see specialists. Additional reasons included easing the PCP's burden for complex patients and difficulty accessing primary care appointments. The PCPs felt uncomfortable initiating conversations with specialists regarding transitioning a patient's care back to the PCP. Some felt disagreeing with a specialist's recommendation could offend them, disrupting future professional collaboration. Another barrier to smooth transition is its dependency on the patient's approval. Patients should be the focus in the decision to transition; however many are misinformed in thinking dual health care is superior to sole care by a PCP.

In this study, there were no interviews with either the specialists or patients involved. It would be helpful to under- stand patient care transition from these two perspectives. This might provide answers to why transitions are difficult. Currently, there are no guidelines to determine when patients are appropriate to be transferred back to their PCPs. Future studies should explore potential models that physicians can use to determine direction of a patient's care. Obstacles like medical stability of a patient and the PCP's experience related to the condition are factors that should be considered. While primary care is much less expensive than specialty care, the growing shortage of PCPs is likely to exacerbate this problem.

Conflict of interest: The authors declare that they do not have a conflict on interest.

Corresponding Author: Jeffrey L Jackson, MD MPH; Medical College of Wisconsin, Milwaukee, WI, USA (e-mail: Jjackson@mcw.edu).

\section{REFERENCES}

1. Kantsiper M, McDonald EL, Geller G, Schockney L, Snyder C, Wolff AC. Transitioning to breast cancer survivorship: perspectives of patients, cancer specialists and primary care providers. J Gen Intern Med. 2009;24(Suppl 2):459-71.

2. Haggstrom DA, Arora NK, Helft P, Clayman ML, Oakley-Girvan I. Follow-up care delivery among colorectal cancer survivors most often seen by primary and subspecialty care physicians. J Gen Intern Med. 2009;24(Suppl 2):4729.

3. Bowman BT, Kleiner A, Bolton WK. Comanagement of diabetic kidney disease by the primary care provider and nephrologist. The Medical clinics of North America 2013;97:157-73.

4. Ackerman SL, Gleason N, Monacelli J, Collado D, Wang M, Ho C, CatschegnPfab S, Gonzales R. When to repatriate? Clinicians' perspectives on the transfer of patient management from specialty to primary care. J Gen Intern Med. DOI: $10.1007 /$ s11606-014-2920-z. 